\title{
Design and Construction of Micro-Controller Based Intrusion Detector
}

\author{
${ }^{1}$ Shoewu, O.O., ${ }^{2}$ Ayangbekun Oluwafemi J. ${ }^{3}$ Johnson Emmanuel O \\ ${ }^{1,3}$ Department of Electronics and Computer Engineering, Lagos State University, Epe Lagos State, Nigeria. \\ ${ }^{2}$ Department of Computer Science, Redeemer's College of Technology \& Management, Mowe Ogun State, \\ Nigeria
}

*Corresponding Author: Shoewu, O.O, Department of Electronics and Computer Engineering, Lagos State University, Epe Lagos State, Nigeria.

\begin{abstract}
This research is based on microcontroller intrusion detector. It is an electrical electronic system interfaced with GSM technology that will sense the presence of an intruder at night, sound an alarm and flash ON and OFF a security light, while sending an SMS to the user alerting them of an impending burglary attack. A small Nokia phone is interfaced and coded here in exchange of a GSM module because it is cheaper, and more rigid than a GSM module. This is to cut down cost of the whole budget.This model have five parts, namely; PIR, GSM phone, an Intel Atmel 89C52 microcontroller, a Siren and an LCD display screen. It further breaks down into 3 units - The interfaced design board, embedded assembly language programming coding and the remote user handset. The interfaced design board comprises of the motion detector (PIR), a Siren, a $100 \mathrm{~W}$ indicator and an embedded system. The embedded software part was developed using assembly language which gives instructions in form of binary codes to the output; namely the LCD display screen, the interfaced GSM and the remote handset of the owner. The whole Design was carried out on a PROTEUS ISIS 7.0. Then, the developed system was tested on several occasions under different conditions and it yielded satisfactory result on the output by displaying "Intruder detected on the LCD while sending SMS directly to the remote owner whenever there is an intrusion to create an efficient, reliable and stress free security system in today's world.
\end{abstract}

Keywords: Alarm, GSM, Intrusion, Security, Sensor

\section{INTRODUCTION}

Breaking and entry is a crime committed in all the countries and towns all over the world. The major problem of every household or establishment owner is that breaking and entry are always done when the owners are unaware of the actions. Despite many burglar products ranging from Bosch, Ekron, Panasonic and Gent to mention a few, intrusion has not reduced because it is easier for the intruder to connive with the security men who are supposed to intervene in the process since the owner of the restricted environment will be unaware at the time of intrusion. There is however the need to carry the owner along at the time of intrusion by interfacing the existing designs with a mobile technology to avoid any form of connivance and faults.

Therefore as security issues has been a major concern, there is need to adopt IT methodological approach properly developed and implemented using telecommunication techniques to avoid chaos and frustrations as well as providing succumb to humanities. This paper however is all about internal security, which deals with the ability to measure and detectintrusions within a certain range of distance from a prohibited location. More importantly the developed system have the ability to signal the owner or controller of the restricted area in any remote location anytime there is an intrusion (Fig. 1). This hereby led to the design and construction of the microcontroller based intrusion detector device to prevent unauthorized access to a restricted area. 


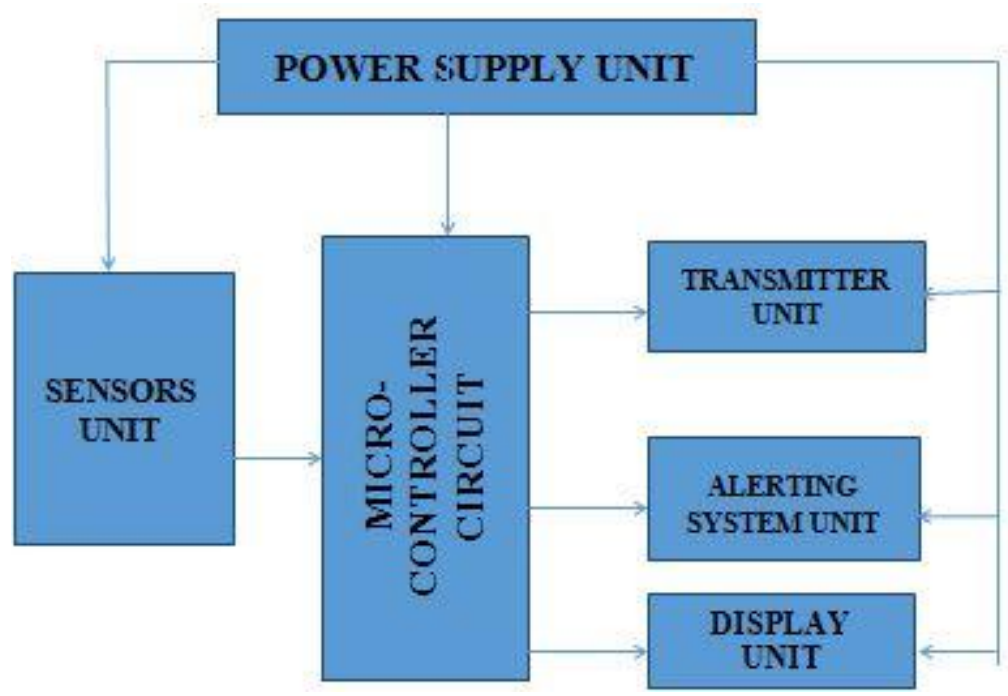

Fig1. System Block Diagram

\section{BRIEF BACKGROUND REVIEW AND MOTIVATION}

It is very interesting that despite hundreds of designs of intrusion detector worldwide, break-in crime is still very much alive because intruders get acquainted to these designs and can easily manoeuvre their way unnoticed around the device. Limited by the fact that alerting system may not be loud enough to be noticed or the fact that the involvement of relevant law enforcement agencies to arrest the situation may be slowed down because it is done at night or that burglars themselves will notice the activation of the alerting system and probably shut down the alarm by brutal force or destroy the security lights.

The first motion detection system radar was pioneered by Heinrich Hertz who studied the properties of waves and found that waves could bounce off an objects and had different speeds. The first motion detector that acted as a burglar alarm was invented in the early 1950s by Samuel Bagno. Bagno applied the fundamentals of radar to ultrasonic waves, a frequency that humans cannot hear, to detect a thief or a fire. Bagno's motion detector also made use of the Doppler -effect, the difference in the frequency of waves of a moving object, like a train sounding louder as it gets closer. Bagno's work could not be reliable due to the presence of dust and fog. In April, 2011 NurmarizahBinti Umar further works on intrusion detector and his design was not a complete success because he was unable to achieve optimum result due to the fact that partial triggering was still not yet eradicated despite his in-built alerting mechanism and lack of external protection for the PIR. Also notifications of intrusion by physically challenged humans were not considered in his design.

Therefore the goal of this research is to overcome the problem being encountered in the previous research using an effective alerting signal in form of an SMS through the aid of a GSM mobile phone interfaced to the board in addition to the existing alarm system whenever there is an intrusion which will be unaware to burglars. The design also incorporates an alerting system that will utilize an audio and visual alerting stimulus through the short message service which will be seen on the owner's mobile device irrespective of the house owner's geographical location.

\section{Methodology}

A microcontroller is acquired and programmed with the basic codes to achieve the desired operation using an assembly language programming compiler being adopted at the micro integrated development environment (MIDE). This complier also converts the assembly language codes into machine or HEX codes, subsequently ready to be burned into the ROM of the microcontroller using a universal programmer and other circuitry which is then tested for ratings verification and defective parts identification.

The circuit diagram was designed using standard electronic components and tested circuits from standardized sources. After the design, the circuit is simulated using basic electronic simulation software such as PROTEUS ISIS to confirm its workability. The whole system is then assembled on a project board to see its workability. After ascertaining this features functionality, the whole system 
will be transferred to a Vero board and gently soldered and enclosed in a plastic case $(6 \mathrm{x} 6$ adoptable box) to prevent bridging of the circuit components (fig. 2).

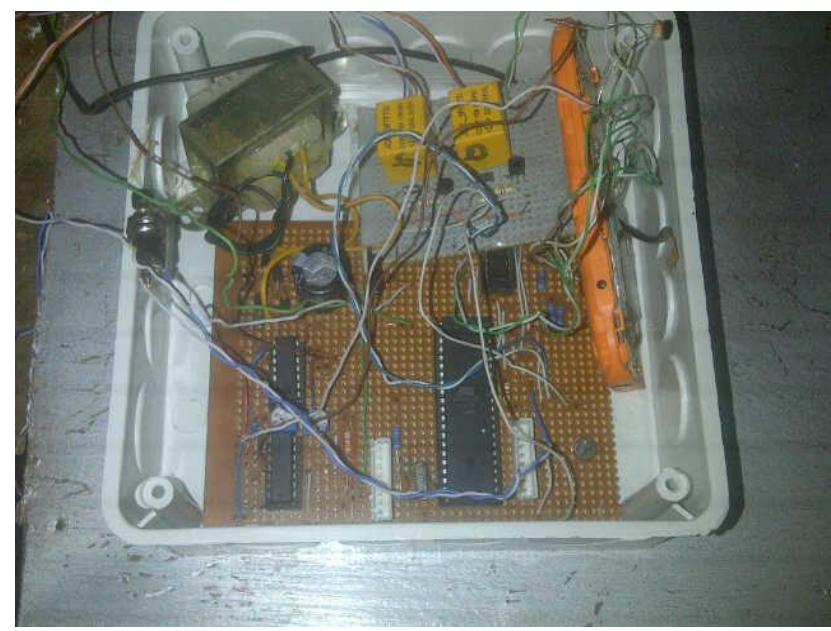

Fig2. Circuitry Internal display

Meanwhile, the external alerting devices, the siren and the security light as well as the passive infrared module and the embedded system circuit, will be mounted on the same plane (Fig. 3).

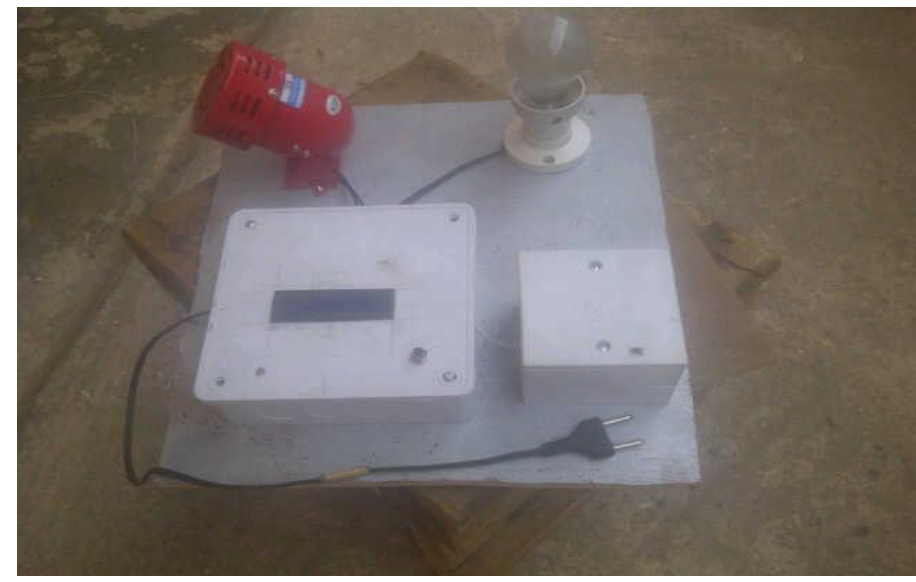

Fig3. Complete Pictorial design View

\section{Circuitry Design And AnAlysis}

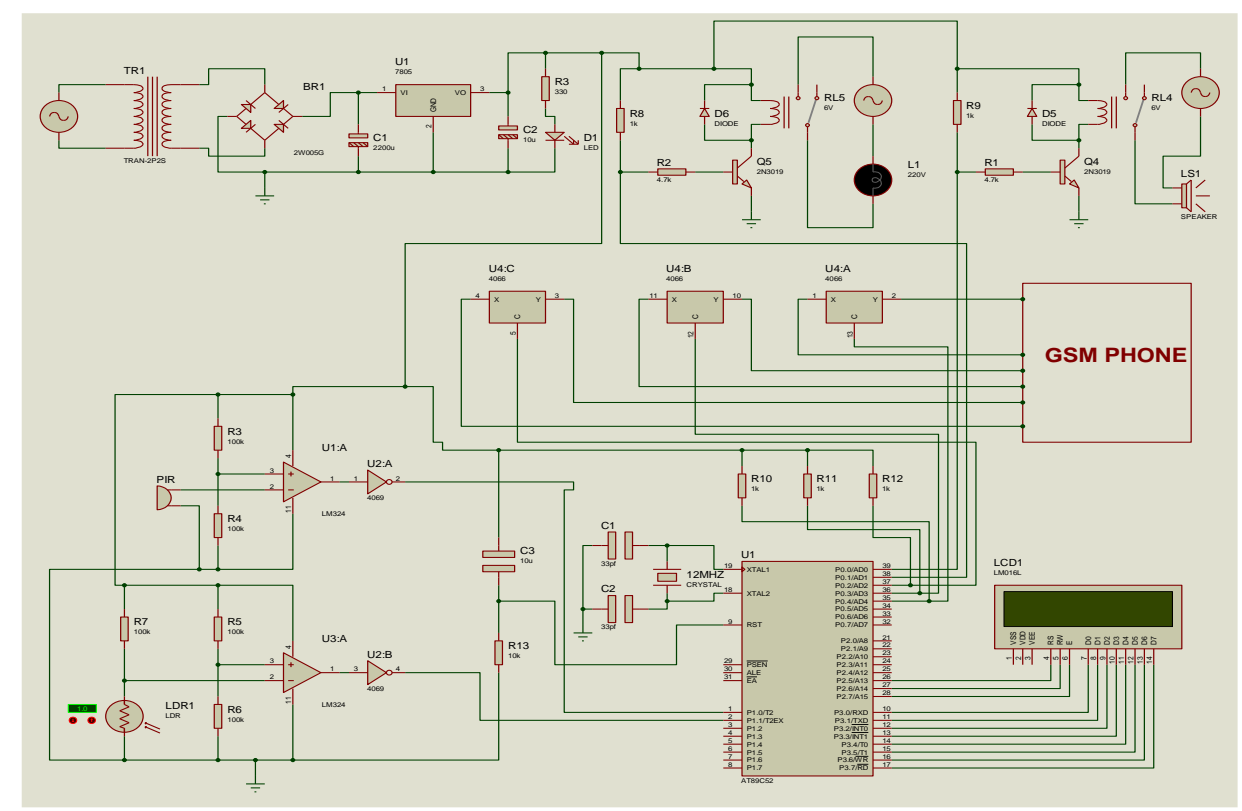

Fig4. Completed circuit design 
From the circuit design, when there is an unauthorized intrusion, the system sends a signal to the transistors Q5 and Q4 to saturate them and turn on relays RL5 and RL4 respectively. The siren and the security lights LS1 and L1 are connected to the relays. So when the relays are turned on, the security light and siren are simultaneously turned on as well. The LCD will display that there is an intruder alert. And using the single-pole, single throw analogue switches $\mathrm{U} 4: \mathrm{B}, \mathrm{U} 4: \mathrm{B}$ and $\mathrm{U} 4: \mathrm{C}$, the microcontroller sends an SMS to the users phone informing them of the burglary in progress. The alarm and security lights will continue to alternatively flash on and off, until a reset button is pressed. Then the whole system goes back to its original default mode while the LCD displays the system is still active.

The automatic control is done using the light dependent resistor, designated LDR1 in the circuit diagram. Biased with R5 and R6, the comparator U3:A outputs a logic 1 during the day. This is possible because in the light, the LDR has a low resistance and consequently, a lower voltage drop across it. This also lowers the voltage presented at the non-inverting input of the comparator and makes the reference set by R5 and R6, to be higher than the value set by the LDR and R7. As the value of the analogue voltage at the non-inverting is higher than the one at the inverting, the comparator outputs logic 1 . The inverter $\mathrm{U} 2$ : $\mathrm{B}$ inverts the signal to logic 0 . This signal is sent to the microcontroller. The embedded program in the microcontroller recognizes logic 0 to disable the motion detector by ignoring the sensor even when it is activated. The LCD display, day mode and that the system is deactivated

Meanwhile during the night, the LDR has a higher resistance, the voltage drop becomes higher, higher than the reference, the comparator gets a higher voltage at the inverting input than its non-inverting input, the output of the comparator goes low, and the inverter inverts this signal to a high and sets it to the microcontroller.

The embedded program in the microcontroller recognizes logic 1 as night, and automatically activate motion detector by monitoring it to know when a burglar approaches. The LCD displays that the system is active and that it is in night mode. However, the whole system operates on a 5 volts Dc power supply. This voltage is gotten from a 220 volts ac supply. A transformer TR1 steps it down, diodes BR1 rectifies the voltage to dc and a capacitor $\mathrm{C} 1$ filters off the ripples. A voltage regulator $\mathrm{U} 1$ outputs the required 5 volts. The siren and the security lights utilize the 220 volts ac power directly from the source

\subsection{Mode of Operation}

The circuit is based on the design and construction of a microcontroller based intruder detector. This is a device that will detect the presence of a burglar and activate alerting system or mechanisms. The detection of the burglar is done by a passive infrared module (PIR sensor) designated PIR in the circuit diagram (Fig. 4). This PIR0016 outputs logic high each time it detects motion by an infrared signal generated by the burglar. Resistor R3 and R4 sets the reference for the comparator U1:A. since the value or R3 and R4 are equal, the analogue output voltage from the reference is approximately half of the supply voltage. This is the value of the voltage that is set into the non-inverting input of the comparator.

Meanwhile, when motion is NOT detected, the reference voltage is higher than the output of the PIR sensor (which is Logic 0) and the output of the comparator is logic 1. However, when motion is detected, the output of the PIR becomes a logic 1, and since the analogue voltage that it outputs is close to the supply voltage, it sets the voltage present at the inverting input of the comparator, to be higher than the reference set by R3 and R4. This makes the comparator to output Logic 0 . This is inverted by the inverter (U2: A) whose basic function is to module the comparator output to a suitable logic level for the microcontroller to utilize. The program embedded into the microcontroller awaits a logic zero to inform it of a burglar's presence.

\subsection{Testing}

The distance of a moving object at different intervals is measured with respect to the pick-up time of the personal infrared sensor alongside the time for the remote owner to receive an SMS (Table 1). The time for the siren to trigger an alarm when the motion detector senses a movement is plotted against the distance of the moving object and the result shown below: 
Table1. Data Collected between distances with time

\begin{tabular}{|c|c|c|}
\hline $\begin{array}{c}\text { Distance from door pointing } \\
\text { to PIR (meters) }\end{array}$ & $\begin{array}{c}\text { Time for PIR to capture motion of } \\
\text { intruder/millisecond }\end{array}$ & $\begin{array}{c}\text { Time to receive SMS from the } \\
\text { interfaced GSM module / phone / } \\
\text { seconds }\end{array}$ \\
\hline 2.5 & 0.0 & 0.0 \\
\hline 2.0 & 3.0 & 5.0 \\
\hline 1.5 & 2.7 & 5.0 \\
\hline 1.0 & 2.5 & 5.0 \\
\hline 0.5 & 1.0 & 5.0 \\
\hline
\end{tabular}

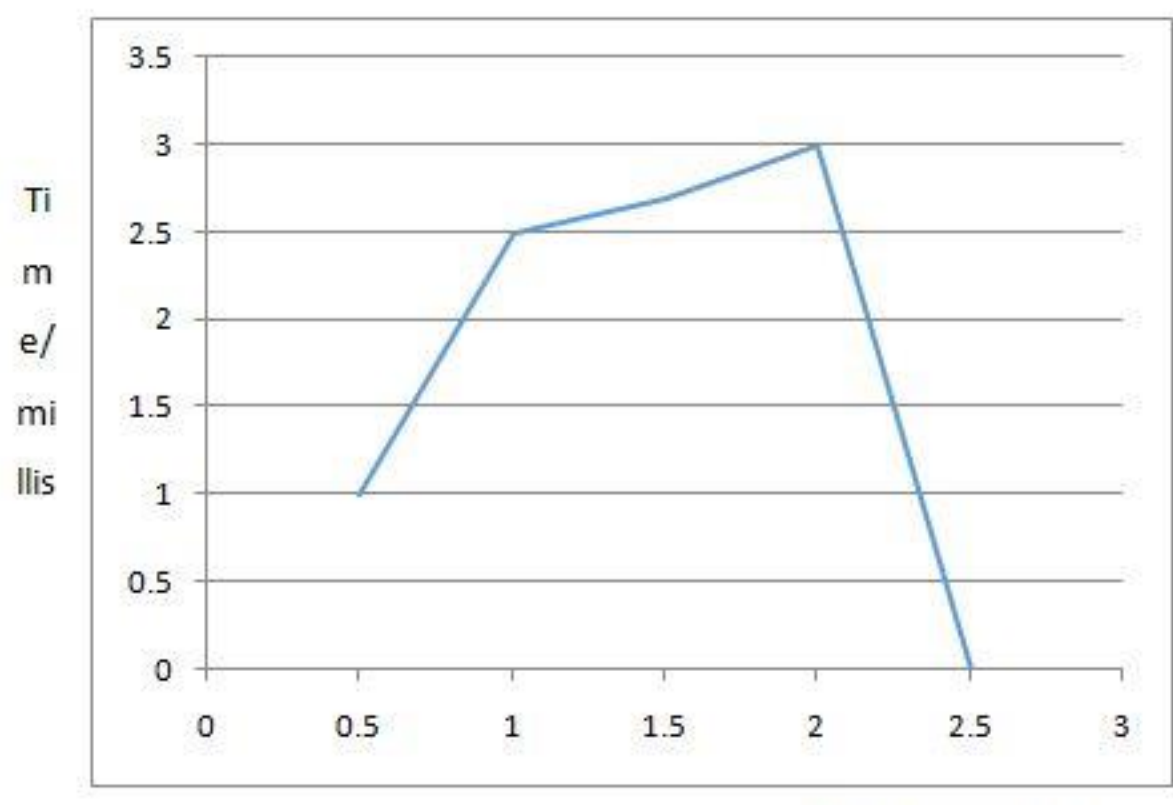

Distance/ meters

Figure5. Graph of Time against Distance of intrusion

From the above graph (Fig. 5), it can be observed that the motion detector used in this research work will trigger the circuit when the object is closer within $2 \mathrm{~m}$ range and of course the remote owner of the restricted location will always get an SMS alert within a very few seconds to take immediate action.

\section{CONCLuSion}

People are getting more and more concerned about how to protect themselves and their homes from emergencies. These emergencies situation cut across theft intrusions and fire attack across homes. This research work provides a means of being able to securely monitor a house by use of sensors integrated with a micro-controller and a GSM unit. With the SMS alert system, it provides an economical and convenient way to notify users of any forms of intrusion or attack into their environment. Therefore, the use of mobile handsets as a client device to receive warning messages implies that the user will not have to carry an additional piece of equipment / device; as most people are already in possession of mobile phone(s) at most time. By using this proposed system the security services like police and fire brigade of a nearby region can also be instantly informed about any intrusion within their geographical area.

\section{REFERENCES}

Gupta J.B” A course in power systems" S.K KATARIA \& SONS $10^{\text {th }}$ Edition July2004. Part3 pp 198-212.

Horowitz P. "The art of Electronics", Cambridge university press second edition p 678

Hughes; "Electrical and electronic technology" Eight edition (2002)

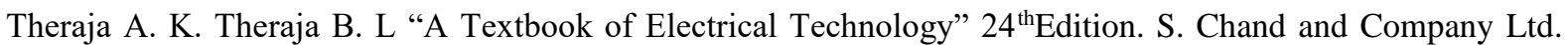
New Delhi (2005) pp 214-230, 2071-2075, 357

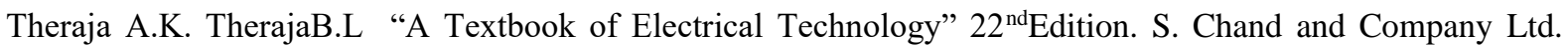
New Delhi (2000) pp1953, 1954 
Miller Rex, Miller Mark Richard" Electric Motors" Willey 6 ${ }^{\text {th }}$ Edition 2000 p35

Tokheim R.L.; "Digital electronics", McGraw hill International Student Edition first edition. www.circuitstoday.com 26/04/2011

www.Alldatasheet.com 27/04/2011

Wikipedia.org: http://en.wikipedia.org/wiki/File:Front-Fresnel_type.JPG

Citation: Shoewu, O.O, (2020)" Design and Construction of Micro-Controller Based Intrusion Detector", International Journal of Innovative Research in Electronics and Communications (IJIREC), 7(4), pp. 1-6. DOI: https://doi.org/10.20431/2349-4050.0704001

Copyright: () 2020 Shoewu, O.O. This is an open-access article distributed under the terms of the Creative Commons Attribution License, which permits unrestricted use, distribution, and reproduction in any medium, provided the original author and source are credited. 